\title{
Death Diagnosis Evaluator
}

National Cancer Institute

\section{Source}

National Cancer Institute. Death Diagnosis Evaluator. NCI Thesaurus. Code C117548.

A person who determines the significance of a death diagnosis assessment. 